\title{
Article \\ Ectopic Overexpression of Maize Heat Stress Transcription Factor ZmHsf05 Confers Drought Tolerance in Transgenic Rice
}

\author{
Weina $\mathrm{Si}^{1}{ }^{1}$, Qizhi Liang ${ }^{1,2}$, Li Chen ${ }^{1}$, Feiyang Song ${ }^{1}$, You Chen ${ }^{1}$ and Haiyang Jiang ${ }^{1, *}$ \\ 1 National Engineering Laboratory of Crop Stress Resistance Breeding, School of Life Sciences, \\ Anhui Agricultural University, Hefei 230036, China; Weinasi@ahau.edu.cn (W.S.); \\ dg20300024@smail.nju.edu.cn (Q.L.); c10226@stu.ahau.edu.cn (L.C.); songfy1026@163.com (F.S.); \\ cy19720386@stu.ahau.edu.cn (Y.C.) \\ 2 State Key Laboratory of Pharmaceutical Biotechnology, School of Life Sciences, \\ Nanjing University, Nanjing 210093, China \\ * Correspondence: hyjiang@ahau.edu.cn; Fax: +0551-65786021
}

Citation: Si, W.; Liang, Q.; Chen, L.; Song, F.; Chen, Y.; Jiang, H. Ectopic Overexpression of Maize Heat Stress Transcription Factor ZmHsf05 Confers Drought Tolerance in Transgenic Rice. Genes 2021, 12, 1568. https://doi.org/ 10.3390 /genes12101568

Academic Editor: Xiquan Gao

Received: 3 September 2021

Accepted: 29 September 2021

Published: 1 October 2021

Publisher's Note: MDPI stays neutral with regard to jurisdictional claims in published maps and institutional affiliations.

Copyright: (c) 2021 by the authors. Licensee MDPI, Basel, Switzerland. This article is an open access article distributed under the terms and conditions of the Creative Commons Attribution (CC BY) license (https:// creativecommons.org/licenses/by/ $4.0 /)$.

\begin{abstract}
Drought is a key factor affecting plant growth and development. Heat shock transcription factors $(H s f s)$ have been reported to respond to diverse abiotic stresses, including drought stress. In the present study, functional characterization of maize heat shock transcription factor 05 ( $\mathrm{ZmHsf05)}$ gene was conducted. Homologous analysis showed that $\mathrm{ZmHsf05}$ belongs to Class A2 Hsfs. The mRNA expression level of $\mathrm{ZmHsf05}$ can be affected by drought, high temperature, salt, and abscisic acid (ABA) treatment. Ectopic overexpression of $\mathrm{ZmHsf05}$ in rice (Oryza sativa) could significantly enhance the drought tolerance. Faced with drought stress, transgenic rice exhibited better phenotypic performance, higher survival rate, higher proline content, and lower leaf water loss rate, compared with wild-type plant Zhonghua11. Additionally, we assessed the agronomic traits of seven transgenic rice lines overexpressing $\mathrm{ZmHsf05}$ and found that $\mathrm{ZmHsf05}$ altered agronomical traits in the field trials. Moreover, rice overexpressing $\mathrm{ZmHsf05}$ was more sensitive to ABA and had either a lower germination rate or shorter shoot length under ABA treatment. The transcription level of key genes in the ABA synthesis and drought-related pathway were significantly improved in transgenic rice after drought stress. Collectively, our results showed that $\mathrm{ZmHsf05}$ could improve drought tolerance in rice, likely in an ABA-dependent manner.
\end{abstract}

Keywords: ZmHsf05; maize; drought; rice; abscisic acid

\section{Introduction}

The uneven distribution and overall shortage of water resources, as well as increasingly severe global warming, have made drought stress one of the most serious threats to plant survival. Moreover, drought can also exacerbate the effects of other biotic and abiotic stresses, including pests, diseases, extreme temperatures, ion stress, etc [1], seriously affecting growth and yield of important crops, such as maize (Zea mays) and rice (Oryza sativa) [2]. It has been reported that drought affects grain yields in a quarter of the world's arable land [3]. Therefore, deciphering the genetic mechanism of plant responses to water deficit and exploring drought-responsive genes would be of great value.

Due to their sessile properties, plants have evolved systemic and effective mechanisms to resist drought stress. Plants respond to drought stress through the integration of sophisticated signaling pathways, resulting in external morphological changes, including changes to plant size, leaf morphology [4-6], stomatal characteristics $[7,8]$ and root development $[9,10]$. This eventually leads to the coordination of plant growth and development. Abscisic acid (ABA) is an important hormone that plays a central role in drought-stress related signaling pathways $[11,12]$. Upon drought stress, ABA rapidly accumulates, giving rise to leaf stomata closure and the activation of many stress-related genes. Thus far, quite a few key transcription factors have been reported to be involved in response to drought 
stress through ABA-dependent pathways. For example, an abscisic acid, stress and ripening (ASR) gene, OsASR5 from an upland rice variety can enhance drought tolerance in rice by regulating ABA biosynthesis and promoting stomatal closure [13]. Additionally, GhWRKY17 negatively regulates drought and salt stress through ABA signaling [14]. In Arabidopsis thaliana, the transcription factor NGATHA1 (NGA1) could enhance resistance to drought stress through the transcriptional activation of NINE-CIS-EPOXYCAROTENOID DIOXYGENASE 3 (NCED3), which encodes a critical enzyme for ABA biosynthesis [15,16]. These drought-responsive transcription factors are present in a considerable quantity or variety [17]. They generally function through the transcriptional regulation of downstream genes, mainly including osmotic adjustment genes, antioxidant metabolism genes and stress-inducing protein genes [18-22].

Heat shock transcription factors $(H s f s)$ are critical components in signal transduction networks that transcriptionally regulate genes responsive to diverse stresses; they are evolutionarily conserved throughout the eukaryotic kingdom [23]. In vertebrates, Drosophila and Caenorhabditis elegans, four, one and one Hsfs have been characterized, respectively [24]. In plants, $H s f s$ families were identified to have diverse gene numbers varying among species, with 21 in Arabidopsis, 25 in rice, 24 in tomato (Solanum lycopersicum) and 52 in soybean (Glycine max), respectively $[23,25,26]$. Moreover, Hsfs in plants shared a typical modular structure $[23,27,28]$. The $\mathrm{N}$-terminal DNA-binding domain (DBD) features by a central helix-turn-helix that specifically recognizes and binds to the heat stress promoter elements (HSE) (5'-AGAAnnTTCT-3'). The oligomerization domain (OD or HR-A/B region) is linked to the DBD by a flexible linker of variable length. According to the length of the flexible linker and the structural characteristics of the HR-A/B region, Hsfs are assigned to $\mathrm{A}, \mathrm{B}$, and $\mathrm{C}$ classes. Class A Hsfs generally function as transcriptional activators that are mediated by the $\mathrm{C}$-terminal short activator peptide motifs (AHA motifs), while typical repressor domains are found in class B Hsfs. In addition, the nuclear localization signal (NLS) for nuclear import and the nuclear export signal (NES) for the receptor-mediated nuclear export are also present in Hsfs.

In line with its nomenclature, the existing functional characterization of HSFs is mainly concentrated in the heat stress-related pathway and were well-documented in several model plants, including Arabidopsis and tomato [29,30]. In addition to heat stress, the importance role of $H s f s$ in distinct stress, including drought stress, has begun to receive attention. AtHsfA6 is transcriptionally regulated by ABA-responsive element binding factor/ABA-responsive element binding protein. Arabidopsis overexpressing AtHsfA6 shows enhanced salt and drought stress tolerance and is hypersensitive to ABA [31]. The combined overexpression of sunflower HaHsfA4 and HaHsfA9 results in a synergistic functional effect on resistance to severe dehydration stress in seedlings [32]. TaHsfA6f from wheat could enhance tolerance to drought, and salt stresses of transgenic Arabidopsis [33]. The overexpression of the OsHSFA3 gene in Arabidopsis can enhance drought tolerance by affecting the levels of $\mathrm{ABA}$ and reactive oxygen species [34]. Drought-responsive HSF in Malus domestica, designated MdHSFA8a, was demonstrated to positively modulate flavonoid synthesis in order to regulate drought tolerance [35].

Maize is one of the most important cereal crops across the world. In maize, 31 nonredundant $H s f$ genes have been identified and were assigned to different classes [36]. Recent research about ZmHsfs has also mainly focused on heat tolerance. ZmHsf04 (ZmHsfA2) and $\mathrm{ZmHsf01}$ can improve thermotolerance in transgenic Arabidopsis [37,38]. In the present study, $\mathrm{ZmHsf05}$ was found to be responsive to drought and could improve the drought tolerance in rice. The present study would provide a gene resource for drought-tolerance breeding in rice and maize.

\section{Materials and Methods}

\subsection{Gene Structural Features and Protein Sequence Alignments}

We obtained the full-length CDS sequence of the $\mathrm{ZmHsf05}$ gene from the online database Phytozome (https:/ / phytozome.jgi.doe.gov/pz/portal.html accessed on 18 April 
2014). To identify all Hsfs from maize, rice and Arabidopsis, proteome of maize were downloaded from MaizeGDB (https: / / maizegdb.org/, accessed on 1 August 2017), and proteomes of rice and Arabidopsis were downloaded from the Phytozome database. Subsequently, a pfam_scan perl script from HMMER3.1 (Maryland, USA) was used to query all of the three proteomes against the Pfam library to detect the candidate Hsfs harboring HSF_DNA-binding domain (PF00447) [39]. The full-length amino acid sequences of all Hsf proteins in three species were aligned and used to construct a neighbor-joining phylogenetic tree by MEGA 7.0(Auckland, New Zealand) [40]. A bootstrap analysis was performed by 1000 replicates. Multiple alignment of ZmHsf05, OsHsfA2e (Os03g58160) and AtHsfA2 (At2g26150) were conducted in MEGA 7.0 and subsequently submitted to ESPript v3.0 (Lyon, France) [41]. Predicted secondary structure of AtHsfA2 were downloaded from AlphaFold Protein Structures Database [42].

\subsection{Plant Materials, Growth Conditions, and Transformation}

The seeds of maize inbred line B73 used in this study came from the resources preserved in our laboratory. Seeds were soaked and planted in nutrient-rich soil in a plant incubator at $28^{\circ} \mathrm{C}$ under $14 \mathrm{~h}$ light and $22^{\circ} \mathrm{Cunder} 10 \mathrm{~h}$ dark. For tissue specific expression analysis of ZmHsf05, leaves, roots, stems, tassels, corn silk, and bract were sampled from B73 seedlings at the adult stage. The rice variety used in the present study was ZH11 (Zhonghua 11), obtained from China Rice Data Center (https:/ / ricedata.cn/variety/varis/ 601422.htm?601422 accessed on 1 August 2005). Rice was grown in nutrient-rich soil or nutrient solution in plant incubators for experimentation at seedling stages at $26^{\circ} \mathrm{C}$ under $14 \mathrm{~h}$ light and $22^{\circ} \mathrm{C}$ under $10 \mathrm{~h}$ dark. The rice nutrient solution we used was Hoagland nutrient solution diluted-5-times. For field experiment, transgenic rice lines, together with wild-type plants, were grown in a paddy field in Anhui agricultural university (Hefei, China).

In the analysis of stress-induced expression patterns, B73 seedling at the three-leaves stage were treated with different abiotic stress, including ABA presence (spraying corn plant leaves with $100 \mu \mathrm{M}$ of $\mathrm{ABA}$ ), simulated drought stress ( $20 \%$ polyethylene glycol 6000$)$ and salinity stress $(200 \mathrm{mM} \mathrm{NaCl})$, and heat stress $\left(42^{\circ} \mathrm{C}\right)$. Leaves were sampled at 0,1 , $3,6,12$, and $24 \mathrm{~h}$. For the analysis of stress-related gene expression, rice seedlings were grown in Hoagland nutrient solution for three weeks and then treated with 20\% PEG. After $3 \mathrm{~h}$ and $6 \mathrm{~h}$ of treatment, leaves of ZH11 and transgenic lines were quickly sampled. All sampled tissues were treated by liquid nitrogen, then refrigerate and store at $-80{ }^{\circ} \mathrm{C}$ for further analysis.

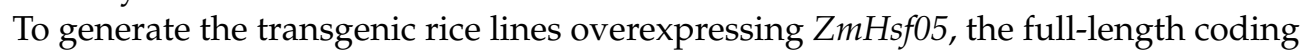
sequence of $\mathrm{ZmHsf05}$ cloned from B73 was digested with $\mathrm{KpnI}$ and $\mathrm{XbaI}$, and inserted into the pCAMBIA1301a vector driven by the cauliflower mosaic virus (CaMV) 35S promoter. Moreover, a $\beta$-glucuronidase (GUS) gene was also under the control of CaMV $35 \mathrm{~S}$ promoter. Primers are listed in Supplementary Table S1. The recombinant plasmid were transferred into Agrobacterium tumefaciens strain GV3101 and the Agrobacteriummediated methods were applied to transform the 35S::ZmHsf05 recombinant plasmid into rice embryonic calli [43]. To obtain positive transgenic lines, hygromycin screening and GUS straining were performed referring to the previous study [44]. Candidate positive transgenic lines were further confirmed by RT-PCR by detecting the expression of $\mathrm{ZmHsf05}$ in ZH11 and transgenic lines. Homozygous T3 progeny transgenic lines were utilized for further phenotypic assessment.

\subsection{Total RNA Extraction and RT-qPCR Analysis}

All corn and rice RNA were extracted using the TRIzol reagent (Invitrogen). All template cDNAs were obtained using the TaKaRa's reverse transcription kit. The RTqPCR reaction program was: $95^{\circ} \mathrm{C} 5 \mathrm{~min}$, followed by 40 cycles of $95^{\circ} \mathrm{C}$ for $10 \mathrm{~s}, 60^{\circ} \mathrm{C}$ for $30 \mathrm{~s}$. We added a dissolution profile steps after all cycles. The amplified signal and data were processed using the comparative $\mathrm{Ct}$ method ( $\Delta \Delta \mathrm{Ct}$ method) [45]. ZmActin1 
(Zm00001d010159) and OsActin1 (Os03g50885) were used as controls. Each quantitation experiment included 3 biological replicates and 3 technical replicates. The primer sequences used in this study are shown in Supplementary Table S1.

\subsection{Phenotypic Analysis}

For phenotypic analysis of transgenic rice under drought stress, rice seedlings were cultivated in nutrient-rich soil for three weeks in normal condition and withheld water for 7 days. Seedlings were subsequently rewatered for 3 days to observe the phenotype. For the stimulated drought experiments, rice seedlings cultured in the nutrient solution for three weeks and then treated with 20\% PEG6000 for $12 \mathrm{~h}$. Treated seedlings were further restored with the nutrient solution for 5 days.

\subsection{Measurement of Physiological Indices}

The water loss rate was estimated according to the methods described by Wei et al. [46]. Leaves of the seedlings in the same position were detached and their fresh weight was measured. Then, the detached leaves were exposed in the air to induce dehydration. Desiccated weight was assessed at $1 \mathrm{~h}, 2 \mathrm{~h}$ and $3 \mathrm{~h}$, respectively. Water loss rate $(\%)=($ fresh weight - desiccated weight) $/ \mathrm{FW} \times 100$. Proline content was determined following the proline assay kit (A107-1-1, Nanjing Jiancheng Bioengineering Institute, Nanjing, China), with homogenized $0.1 \mathrm{mg}$ of homogenized fresh leaves. Absorbance values were measured at $520 \mathrm{~nm}$.

\subsection{Subcellular Localization Analysis}

We constructed the full-length $\mathrm{ZmHsf05}$ CDS with the terminator removed on the pCAMBIA1305 vector which has a GFP flag and a CaMV 35S promoter by adding two restriction sites (Xba I and Sma I). Primers were listed in Supplementary Table S1. Maize protoplasts were prepared using the leaves of two-week-old etiolated seedlings according to the method reported by Gao et al. [47]. The resulting ZmHsf05-GFP recombinant plasmid, positive control 35S::GFP, and nucleus marker NLS-mcherry were placed into the prepared maize protoplasts by PEG-calcium mediated method, followed by a $18 \mathrm{~h}$ incubation in the dark at $28^{\circ} \mathrm{C}$ for transient expression. The fluorescence signals of the recombinant proteins in protoplast cells were observed by a the confocal laser scanning microscope (ZEISS LSM 880 with Airyscan, Germany) with GFP (488 nm excitation, 522-572 nm emission) and mCherry (587 $\mathrm{nm}$ excitation, 590-630 $\mathrm{nm}$ emission).

\subsection{Transactivation Activity Assays}

The Full-length CDS sequence of ZmHsf05 was fused to the pGBKT7 vector via homologous recombination. PGBKT7-p53 + pGADT7-T was used as a positive control, and pGBKT7 was used as a negative control. Additionally, $1 \times$ TE/LiAc was used to turn yeast strain AH109 into competent yeast. PEG/LiAc, DMSO, $1 \times$ TE buffer, and salmon sperm DNA were used to transform the constructed plasmid into yeast competent cells. Single-deficient medium SD/-Trp and triple-deficient medium SD/-Trp/-His/-Leu were purchased from TakaRa company.

\subsection{Statistical Analysis}

Fisher's least significant difference multiple test or Student's $t$-test was performed via the DPS software to identify the statistical significance of the data [48].

\section{Results}

\subsection{Molecular Characterization of $\mathrm{ZmHsf05}$ Sequence}

A previously identified Hsf gene [49] GRMZM2G132971 (B73 v4 gene ID: Zm00001d03 4433), named as $\mathrm{ZmHsf05}$, was investigated in the present study. The coding sequence (CDS) of ZmHsf05 is $1080 \mathrm{bp}$ in length and encodes a protein harboring an HSF_DNA-bind domain (PF00447). Moreover, homologous analysis was performed through phylogenic 
reconstruction with all Hsfs proteins from maize, rice, and Arabidopsis (Figure 1A). Results showed that ZmHsf05 was clustered within the HsfA2 clade and showed an orthologous evolutionary relationship with OsHsfA2e. The domain composition and signature of both the OsHsfA2e (Os03g58160) and AtHsfA2 (At2g26150) has been well characterized. Thus, to better analyze the protein structure of $\mathrm{ZmHsf05}$, protein sequence of $\mathrm{ZmHsf05}$ was aligned to AtHsfA2 and OsHsfA2e (Figure 1B). As expected, ZmHsf05 showed high sequence similarity with AtHsfA2 and OsHsfA2e. Additionally, amino acid sequences and position of N-terminated DNA binding domain (DBD), oligomerization domain (OD), nuclear localization signal (NLS), and aromatics hydrophobic and acidic amino acid residues (AHA) and nuclear export signal (NES) of ZmHsf05 were shown in Figure 1B, according to previous annotation of AtHsfA2 and OsHsfA2e (Figure 1B). Those typical domains were conserved among the three proteins, while only sequences of NES were variable.

\subsection{Tissue-Specific and Stress-Induced Expression Pattern of ZmHsfo5}

The tissue-specific and stress-induced expression profiles of $\mathrm{ZmHsf05}$ were further investigated. We first measured the expression patterns of $\mathrm{ZmHsf05}$ in various tissues of maize under normal conditions using a quantitative real-time polymerase chain reaction (RT-qPCR), including the root, stem, leaf, tassel, corn silk, and bract. The results showed that $\mathrm{ZmHsf05}$ was expressed in all surveyed tissues and organs. In stems and leaves, ZmHsf05 showed the highest expression level (Figure 2A). Previous reports have implied that $H s f s$ may be related to abiotic stresses; thus, an expression profiles analysis was further conducted to investigate whether $\mathrm{ZmHsf05}$ can be induced by various types of abiotic stress. Similarly, we used RT-qPCR to determine the transcription levels of $\mathrm{ZmHsf05}$ under distinct abiotic environmental stresses, including high temperature, $\mathrm{ABA}$, salt, and drought treatments (Figure 2B-E). Specifically, 20\% polyethylene glycol 6000 (PEG 6000) was used to simulate drought stress. The results showed that $\mathrm{ZmHsf05}$ can be induced in maize by high temperature, ABA, salt, and drought in maize at different time points after treatment. Overall, ZmHsf05 is mainly expressed in the stems and leaves of maize, and can be differentially induced by various abiotic stresses.

\subsection{Subcellular Location Analysis of $\mathrm{ZmHsf05}$}

The subcellular location of the ZmHsf05 protein was further investigated through transiently expression in the maize protoplast system. The coding sequences of ZmHsf05 were cloned and fused to the N-terminal of green fluorescent protein (GFP) under the control of the CaMV $35 S$ promoter. Then, the recombinant vector was transformed into maize protoplasts. Sixteen hours after transformation, the subcellular location of ZmHsf05 was observed under the confocal laser scanning microscope. As shown in Figure 3, ZmHsf05 was localized in the nucleus, suggesting that $\mathrm{ZmHsf05}$ protein may function in the nucleus.

\subsection{ZmHsf05 Has Transactivation Activity in Yeast}

To investigate whether $\mathrm{ZmHsf05}$ has transactivation activity, a yeast assay system was used. The full-length CDS of ZmHsfo5 was fused to the GAL4 DBD in the pGBKT7 vector. The recombinant plasmid was then transformed into the AH109 yeast strain (Figure 4A). At the same time, pGBKT7-53+pGADT7-T were used as positive controls and the empty vector pGBKT7 was used as a negative controls. As shown in Figure $4 B$, the positive controls and pGBKT7-ZmHsf05 can grow on SD/-Trp single deficiency medium and SD/-Trp/-His/-Leu/-X- $\alpha$-gal triple deficiency medium. They can also turn blue on the SD/-Trp/-His/-Leu/-X- $\alpha$-gal triple deficiency medium. The negative control can grow on SD/-Trp single deficiency medium but not on the SD/-Trp/-His/-Leu/-X- $\alpha$-gal triple deficiency medium. Negative controls cannot turn blue either. Based on the above results, we can observe that $\mathrm{ZmHsf05}$ exhibits transactivation activity in yeast. 


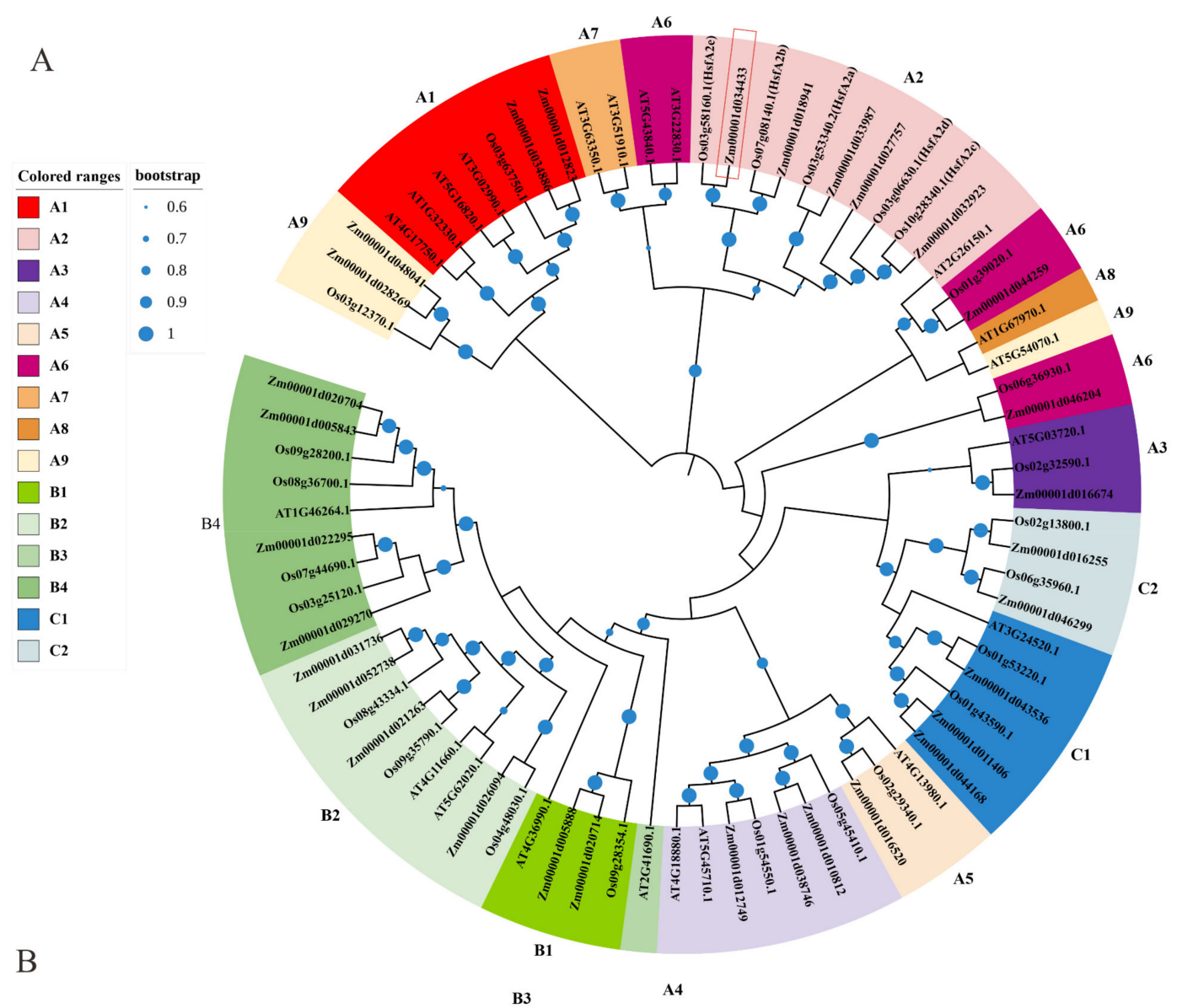

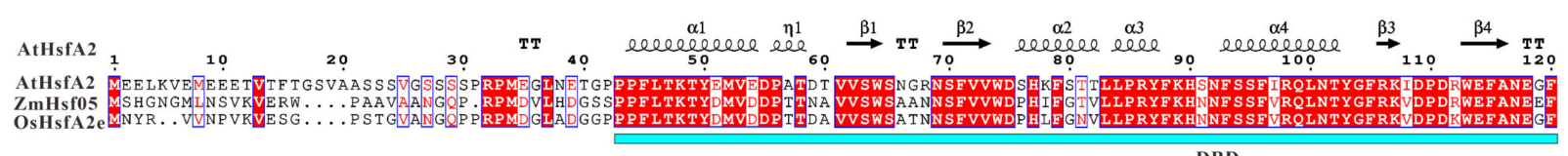

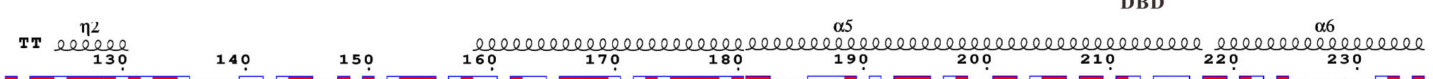

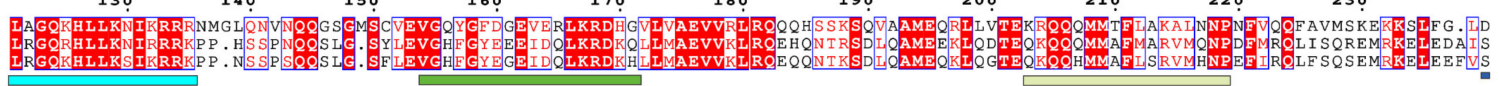

HR-A

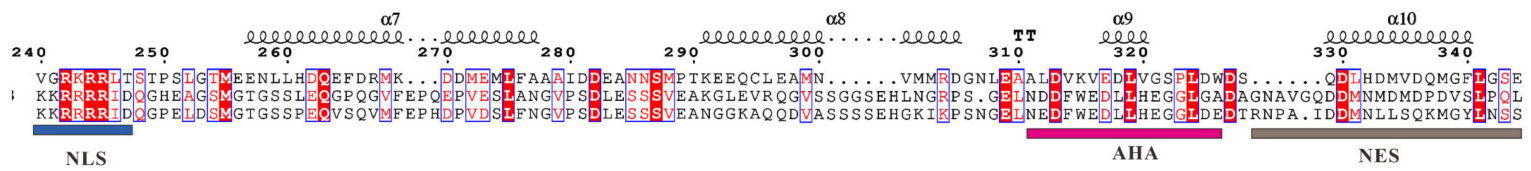

NLS

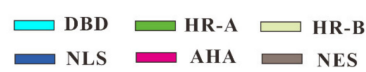

Figure 1. Homologous analysis of heat shock transcription factor 05 (ZmHsf05) with Hsfs in maize (Zea mays), rice (Oryza sativa) and Arabidopsis thaliana. (A) The phylogenetic tree was constructed using the neighbor-joining method. Heat shock transcription factors (Hsfs) were classified into different sub-classes according to their annotation in the Uniprot website and marked with a different color. Nodes with bootstrap values larger than 0.6 are shown by blue circles. ZmHsf05 is emphasized by a red box. Zm, Os, and AT is short for maize, rice and Arabidopsis thaliana, respectively. (B) Multiple sequences alignments of ZmHsf05, AtHsfA2 and OsHsfA2e. Identical and similar residues are boxed in red and white, respectively. Domain composition and position were marked with colored boxes below the alignments (DBD, DNA binding domain; OD, oligomerization domain, NLS, nuclear localization signal; AHA, aromatics hydrophobic and acidic amino acid residues; NES, nuclear export signal). The predicted second structure of AtHsfA2 was present above the alignments (helix, squiggles, $\beta$-strands, arrows; turns, TT letters). 

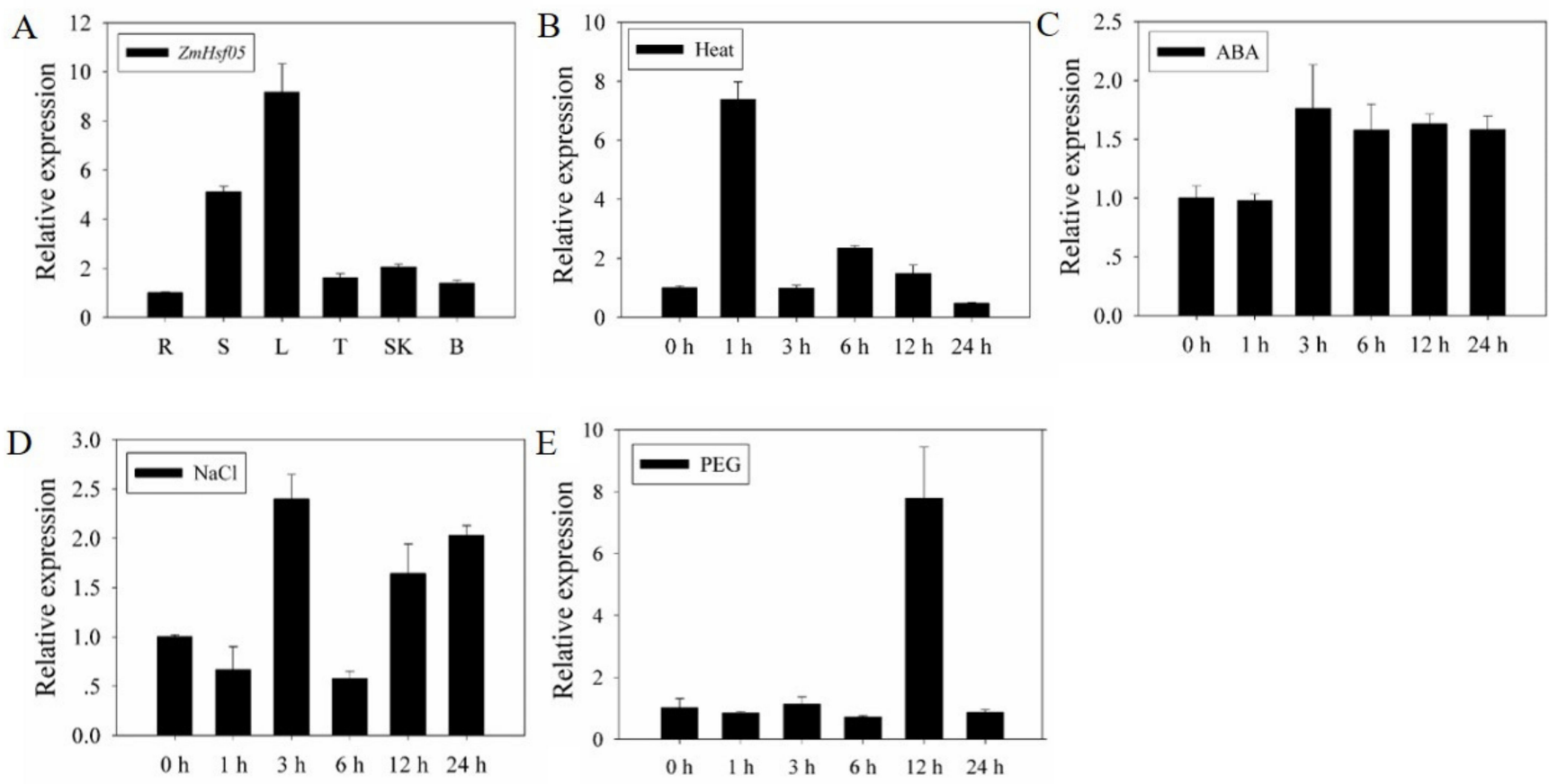

Figure 2. Expression patterns analysis of $\mathrm{ZmHsf05}$ in maize. (A) Tissue-specific expression of ZmHsf05 gene in maize under normal conditions. R (root); S (stem); L (leaf); T (tassel); SK (corn silk); B (bract). (B) Expression patterns of ZmHsf05 in leaves under $42{ }^{\circ} \mathrm{C}$. (C) Expression patterns of ZmHsf05 in leaves under $100 \mu \mathrm{M}$ ABA. (D) Expression patterns of ZmHsf05 in leaves under $200 \mathrm{mM} \mathrm{NaCl}$. (E) Expression patterns of ZmHsf05 in leaves under 20\% PEG6000. The ZmActin-1 gene was used as the internal control for normalization. Vertical bars indicate means \pm SEs $(n=3)$.
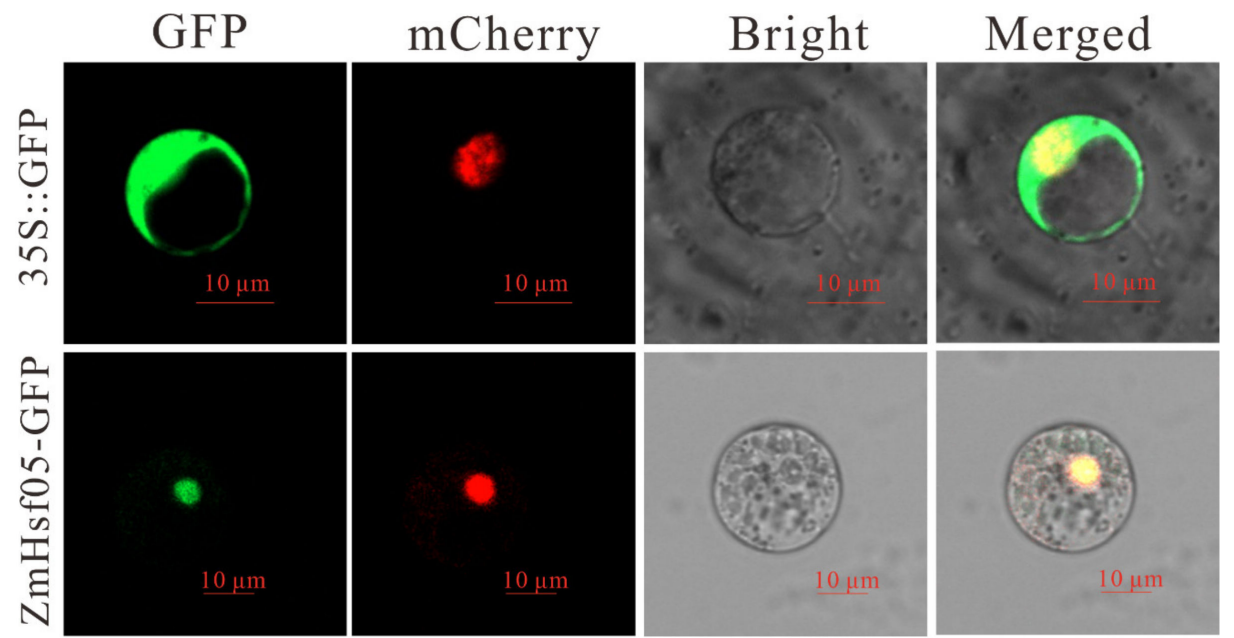

Figure 3. Subcellular localization of the ZmHsf05 protein. Subcellular localization of the ZmHsf05 protein in maize protoplast cells. The recombinant fluorescent proteins $\mathrm{ZmHsf05}$ and GFP are localized in the nucleus, overlapped with the red fluorescent protein expressed from nuclear localization signaling protein (NLS). The 35S:GFP is used as a blank control, and ZmHsf05-GFP is the subcellular localization fusion vector of $\mathrm{ZmHsf05}$. The green is the GFP protein signal, and the red fluorescence represents the nuclear localization signaling protein (NLS). (35S, CaMV 35S promoter; GFP, green fluorescent protein). 


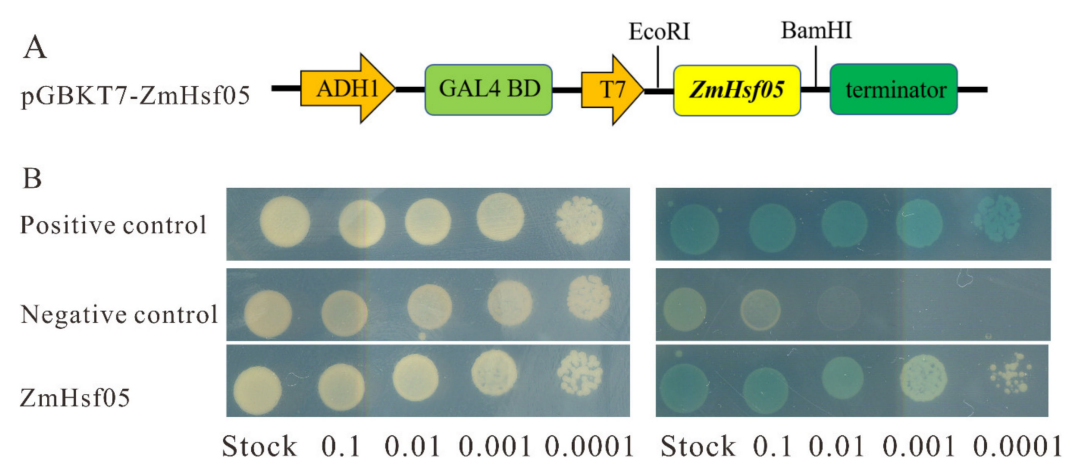

Figure 4. Transactivation activity analysis of $\mathrm{ZmHsf05}$. (A) Schematic diagram of the fused vector used in the experiment. The full length of ZmHsf05 cDNA to the GAL4 DNA-binding domian (GAL4 $\mathrm{BD})$ coding region in the fused vector. Expression of $\mathrm{ZmHsf05}$ was driven by $\mathrm{T} 7$, while expression of GAL4 BD was driven by promoter of ADH1 (Alcohol dehydrogenase 1) (B) The result of the transactivation activity analysis. The yeast was transformed with positive control, negative control and pGBKT7-ZmHsf05 fused vectors, respectively, and grown on SD/-Trp/-His/-Leu/-X- $\alpha$-gal triple deficiency medium. Positive control: pGBKT7-53+pGADT7-T, Negative control: pGBKT7.

\subsection{Overexpression of ZmHsf05 in Rice Alters Agronomical Traits in the Field Trials}

To better investigate the important roles of $\mathrm{ZmHsf05}$ in response to environmental stress, ZmHsf05 was overexpressed in rice cultivar Zhonghua11 (ZH11) driven by the strong and constitutively active 35S promoter. The transgenic rice was generated by Agrobacterium-mediated transformation and confirmed by hygromycin resistance, the positive staining of the GUS marker, and amplifying the sequences of the recombinant vector via PCR. Finally, seven transgenic lines were obtained (Supplementary Figure S1A,B). In addition, we also detected the expression of the $\mathrm{ZmHsf05}$ in transgenic rice using quantitative and semi-quantitative methods (Supplementary Figure S1C,D).

Seven independent transgenic lines and the wild-type plant ZH11 were grown in field condition. Their agronomic traits were thoroughly analyzed to estimate whether overexpressing $\mathrm{ZmHsf05}$ in rice would influence the growth and development in the field trials. The plant height of six transgenic rice lines was significantly higher than that of the wild-type plants (Figure 5C). Moreover, transgenic rice lines have more effective tillers (Figure 5D), longer panicles (Figure 5A,E) than those of ZH11. Additionally, grains of transgenic lines were approximately equal to those of wild-type plants. Whereas, grains of transgenic lines were a little bit longer, but thinner (Figure 5B,F,G). Intriguingly, the 1000-seed weight were significantly reduced in four transgenic lines compared to wild type plants, the other three transgenic lines also showed similar decreasing tendency (Figure $5 \mathrm{H}$ ). The results demonstrated that overexpression of $\mathrm{ZmHsf05}$ in rice can promote effective tiller emergence, improve plant height, increase panicle length, modify seed morphology and cause serious damage to seed weight. The transgenic lines have a considerably larger number of effective tillers, which suggested overexpressing $\mathrm{ZmHsf05}$ in rice may have great potential to increase yield production.

\subsection{Overexpression of ZmHsf05 Enhances Drought Tolerance in Rice}

Subsequently, in order to investigate whether ZmHsf05 can improve the drought tolerance of transgenic rice, we selected three transgenic rice lines for drought experiments. The three transgenic rice lines with $\mathrm{ZmHsf05}$ overexpression lines (OE1, OE2, OE3) and ZH11 were cultured in soil. Three weeks after planting, the rice lines had water withheld water for about 7 days, resulting in the leaves wilting. Then, the surveyed rice lines were watered and allowed to recover for 3 days. As shown in our results, the transgenic rice lines showed better phenotypic performances after exposure to drought treatment for 7 days or recovering for 3 days (Figure 6A-C). Moreover, the survival rate of the transgenic rice and ZH11 further verified our phenotypic results (Figure 6D). After the drought treatment, the survival rate of transgenic rice was significantly higher than that of ZH11. 

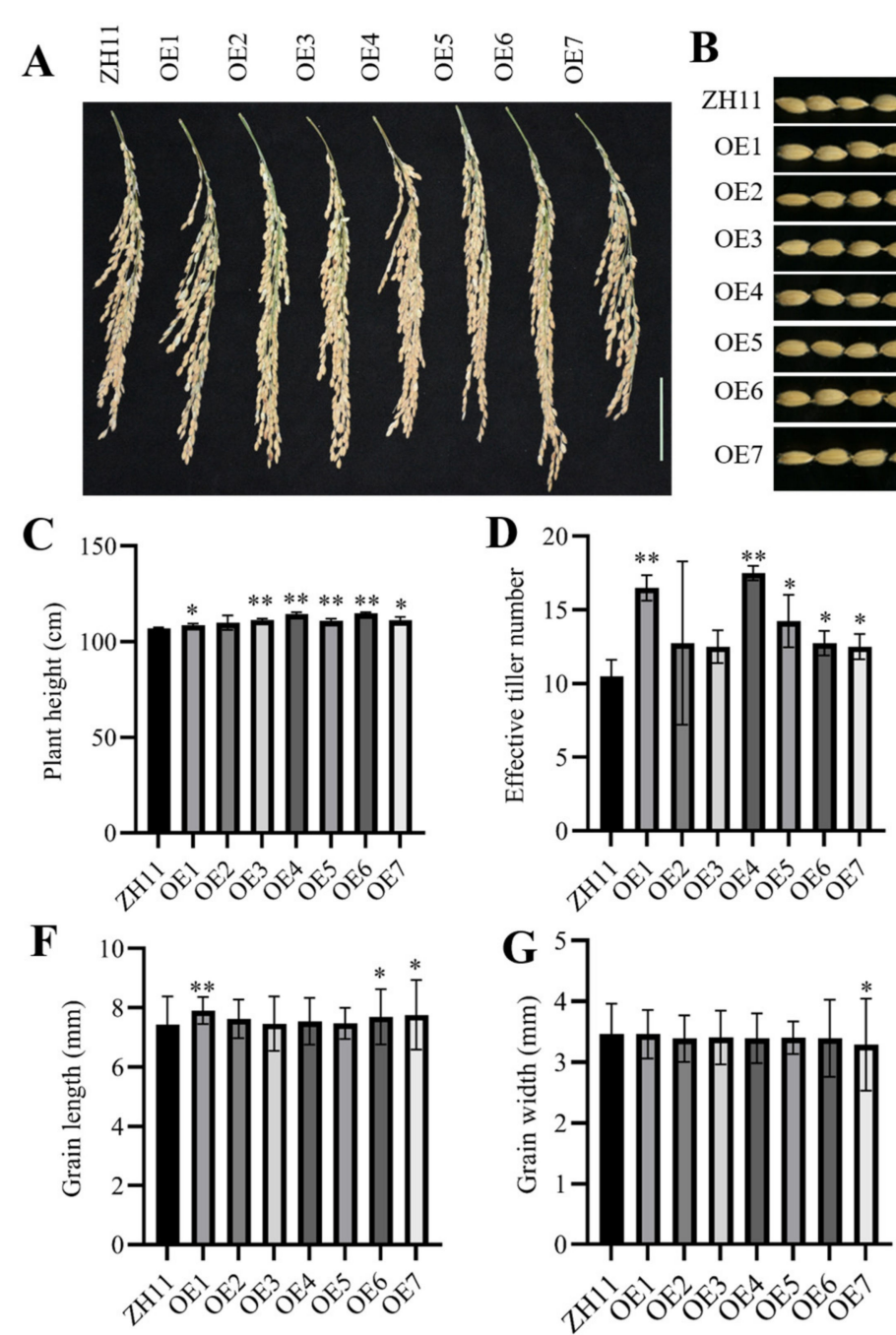

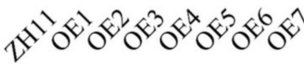

B
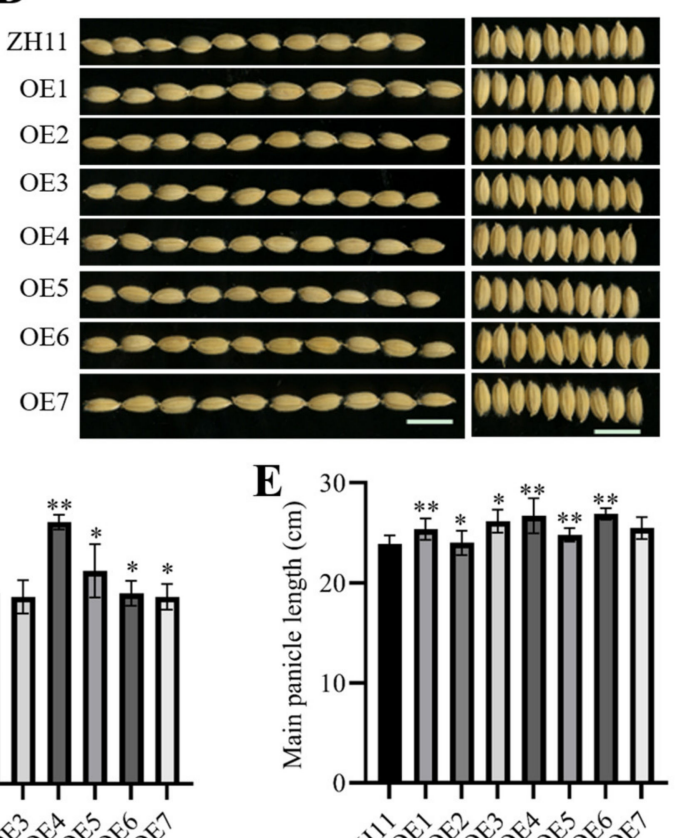

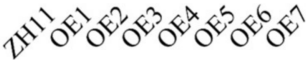
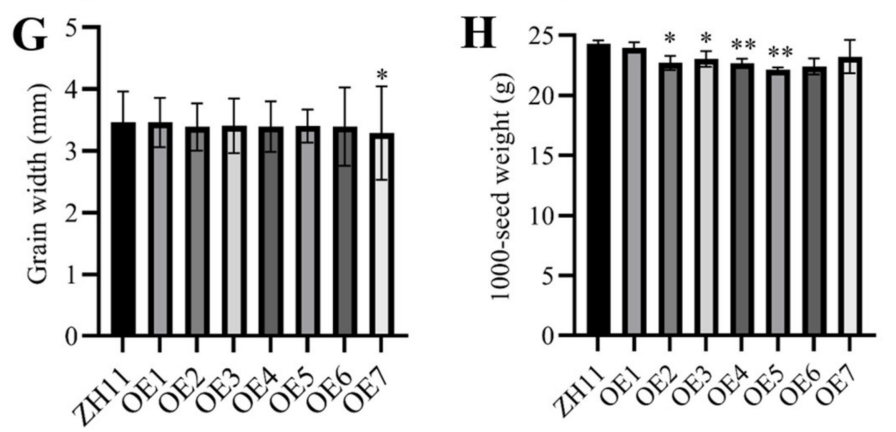

Figure 5. Overexpression of $\mathrm{ZmHsf05}$ in rice alters agronomical traits in field trials. Wild-type rice variety ZH11 (Zhonghua 11) and seven independent transgenic rice lines were used (OE1, OE2, OE3, OE4, OE5, OE6 and OE7). (A) Mature ZH11 and transgenic rice panicles. (Scale bar, $5 \mathrm{~cm}$.) (B) Seed length (left panel), and seed width (right panel) for ten seeds in a row (Scale bar, $1 \mathrm{~cm}$.). (C) Plant height $(n=5)$. (D) Effective tiller number $(n=5)$. (E) Main panicle length $(n=5)$. (F) Grain length $(n=90)$. (G) Grain width $(n=95)$. (H) 1000-seed weight $(n=3)$ were evaluated for overexpression transgenic lines and wild-type plants, respectively. Students' $t$-test was performed for statistics analysis, ${ }^{*}$ denotes $p<0.05,{ }^{* *}$ denotes for $p<0.01, \mathrm{n}$ represents the number of repetitions that have been determined.

In addition, we used PEG to simulate the drought treatment of transgenic rice. After three weeks of culturing in five-times-diluted Hoagland nutrient solution, we used $20 \%$ PEG to simulate drought treatment for $12 \mathrm{~h}$ and then restored the culture with five- timesdiluted Hoagland nutrient solution for 5 days. Before the simulated drought treatment, the growth status of transgenic plants and wild-type ZH11 were similar; however, after $12 \mathrm{~h}$ of simulated drought and cultivation had been resumed for $12 \mathrm{~h}$, the growth status of transgenic rice was apparently evidently better than that of ZH11 (Figure 7A). 


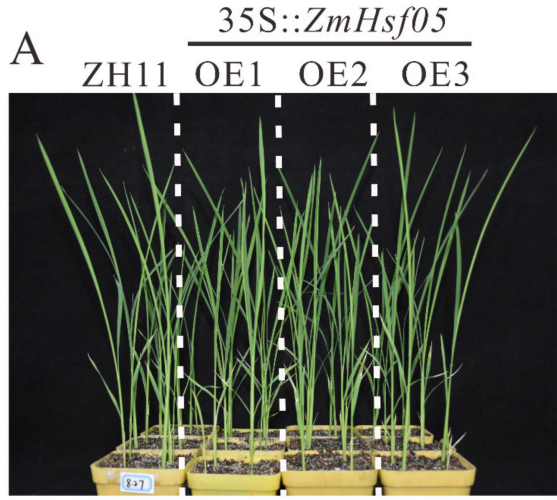

Before treatment

C

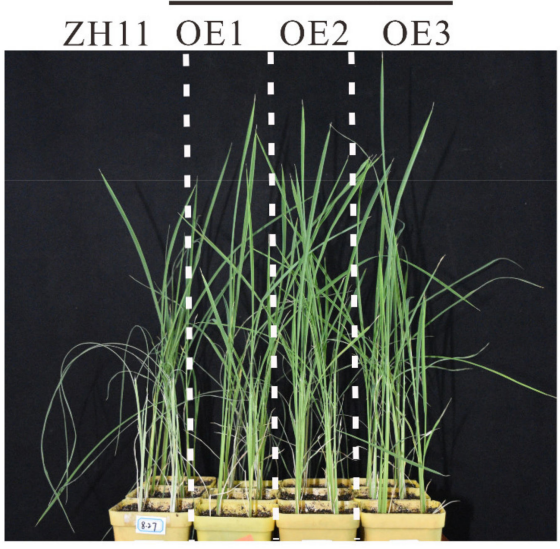

Recovery for 3 days

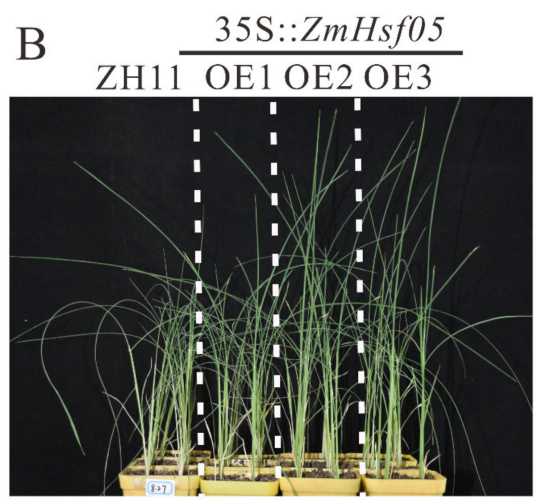

Drought for 7 days

D

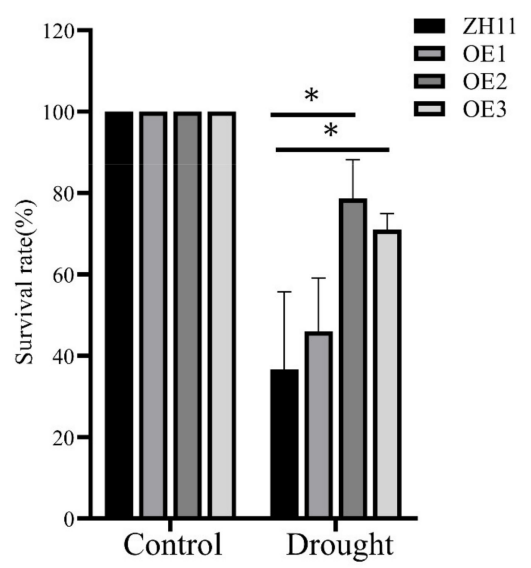

Figure 6. Drought tolerance analysis of rice with $\mathrm{ZmHsf05}$ overexpression in soil. Three transgenic rice $\mathrm{ZmHsf05}$ overexpression lines (OE1, OE2, and OE3) and wild-type $\mathrm{ZH} 11$ were cultured in soil. Rice were grown for three weeks at normal conditions (A), the watering was stopped and the drought treatment was carried out for 7 days (B). After the appearance of the phenotype, we re-cultivated the rice seedlings by watering them for 3 days (C). (D) Statistics of the survival rate of overexpression lines and WT after drought treatment. Vertical bars indicate means \pm SEs $(n=3) .{ }^{*}, p<0.05$ (Student's $t$-test).

Free proline is an important metabolite in drought stress, benefiting the maintenance of cellular homeostasis upon environmental stress. The accumulation and mobilization of proline are believed to be coincidental with the trait of drought tolerance [46]. To further decipher the physiological basis underlying drought tolerance in transgenic rice, the proline contents of $\mathrm{ZH} 11$ and transgenic rice were measured before and after the simulated drought treatment. We found that before drought treatment, the proline content in transgenic rice plants was approximately equal to that of $\mathrm{ZH} 11$. Whereas, the proline content in transgenic rice plants was significantly higher than that in $\mathrm{ZH} 11$ (Figure 7B) after drought treatment. In addition, the water loss rate of transgenic rice leaves after the drought treatment was significantly lower (Student's $t$-test, $p<0.05$ ) than that of ZH11, which further verified the above phenotype (Figure 7C). Finally, we concluded that $\mathrm{ZmHsf05}$ can indeed significantly improve the drought tolerance of transgenic rice. 


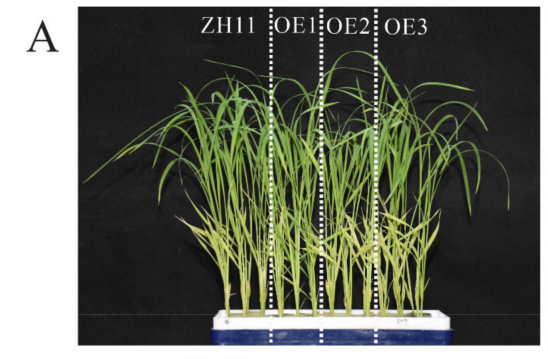

Before treatment

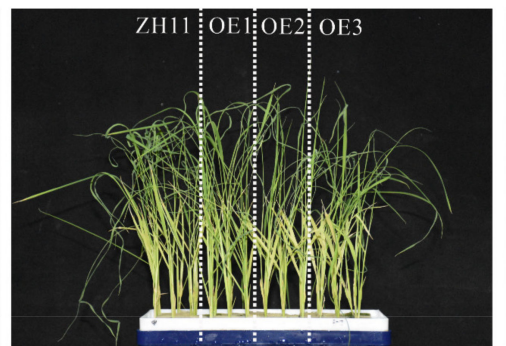

$20 \%$ PEG $12 \mathrm{~h}$

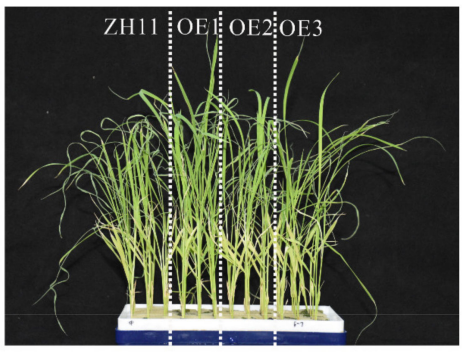

Recovery for 5 days

B

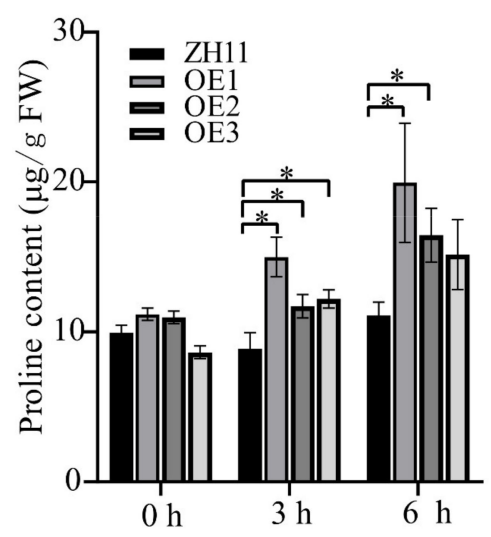

C

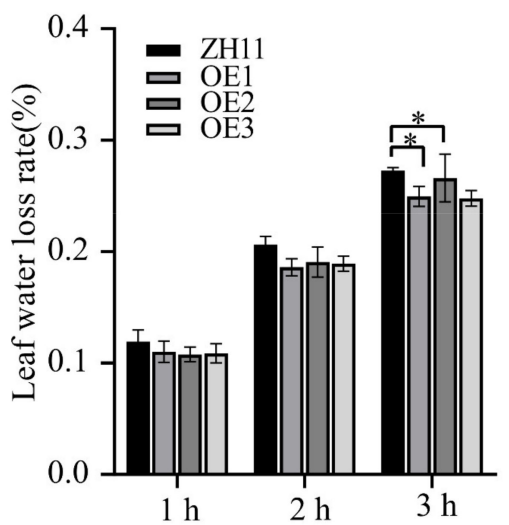

Figure 7. Simulated drought tolerance analysis of rice with $\mathrm{ZmHsf05-overexpression} \mathrm{rice.} \mathrm{(A)} \mathrm{Phenotypic} \mathrm{performance} \mathrm{of}$ transgenic rice before and after simulated drought treatment. Three transgenic rice ZmHsf05-overexpression lines (OE1, OE2 and OE3) and wild-type ZH11 lines were cultured in 5-times-diluted Hoagland nutrient solution supplemented with 20\% PEG6000. (B) Three-week-old rice seedlings were subjected to 25\% PEG6000 simulated drought treatment for $3 \mathrm{~h}$ and $6 \mathrm{~h}$ to determine the content of proline. Three biological replicates were used for each experiment. Vertical bars indicate means \pm SEs $(n=3) .{ }^{*}, p<0.05$ (Student's $t$-test). (C) Three-week-old rice seedling leaves were subjected to $1 \mathrm{~h}, 2 \mathrm{~h}$ and $3 \mathrm{~h}$ in vitro leaf water loss rate measurements.

\subsection{Overexpression of ZmHsf05 Increases Sensitivity to Exogenous ABA Treatment}

$\mathrm{ABA}$ is an essential hormone involved in plant responses to drought stress [12]. To test whether $\mathrm{ZmHsf05}$ regulated drought stress in an ABA-dependent manner, germination and post-germination tests were implemented. Seeds of $\mathrm{ZH} 11$ and transgenic rice were germinated in $\mathrm{H}_{2} \mathrm{O}$ (control) and $2 \mu \mathrm{M}$ of $\mathrm{ABA}$ solution, respectively. Under control conditions, transgenic lines showed similar germination times and germination rates to ZH11 (Figure $8 \mathrm{~A}, \mathrm{~B}$ ), whereas, after treatment with $2 \mu \mathrm{M}$ of ABA, the germination time was significantly delayed and the germination rate was significantly decreased in transgenic rice lines, compared with ZH11 (Figure 8C,D). Then, under normal circumstances, we selected rice seeds with consistent germination rates and estimated their sensitivity to different concentrations of ABA. After treatment for 6 days, we found that the shoot growth of rice with $\mathrm{ZmHsf05}$ overexpression was significantly decreased compared to that of wild-type ZH11 under $5 \mu \mathrm{M}$ of ABA and $10 \mu \mathrm{M}$ of ABA treatment (Figure 8E-F). The results indicate that the application of exogenous ABA strongly inhibited the shoot growth in the rice with transgenic $\mathrm{ZmHsf05}$ overexpression compared with the ZH11.

These data indicated that the overexpression of $\mathrm{ZmHsf05}$ in rice could increase the sensitivity of transgenic rice to exogenous ABA during seed germination and shoot growth. 
A

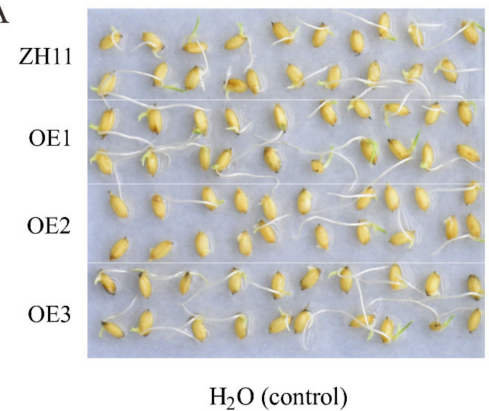

$\mathrm{C}$
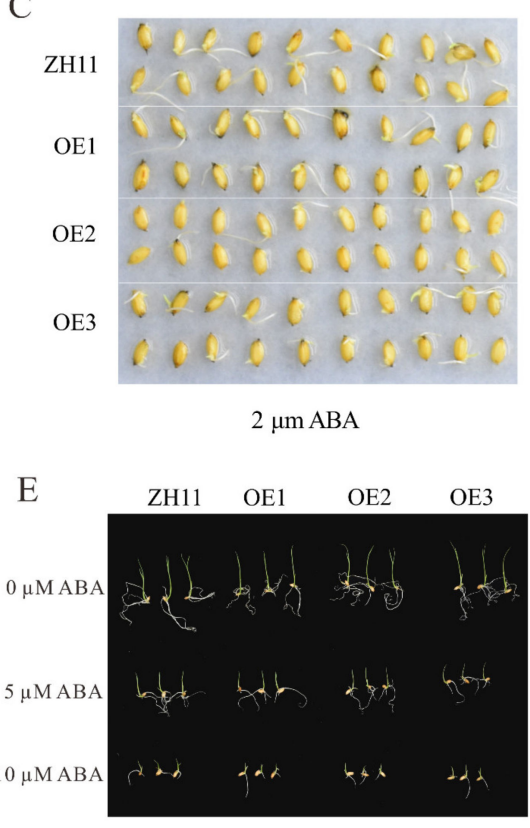

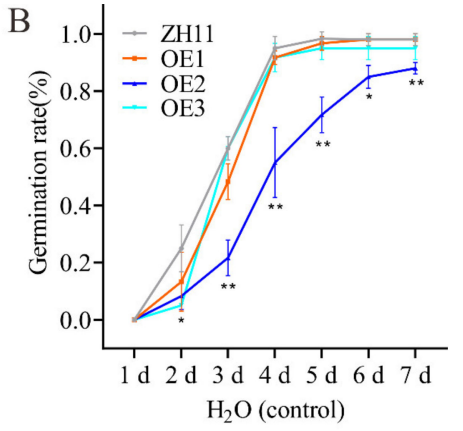

$\mathrm{D}$
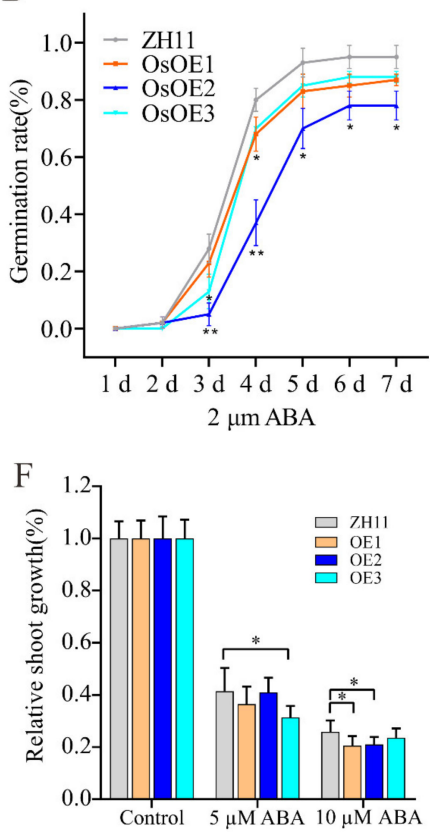

Figure 8. ZmHsfo5 influences seed germination and shoot growth. Each experiment utilizes three transgenic rice lines (OE1, OE2, and OE3) and wild-type ZH11. (A) Germination performance of transgenic rice and $\mathrm{ZH} 11$ in $\mathrm{H}_{2} \mathrm{O}$ at seven days after initiation. (B) Calculation and statistical analysis of the germination rate of transgenic and ZH11 rice seed in water. A seed was suggested to germinate when the length of radicle was longer than half of the seed. (C) Germination performance of transgenic rice and ZH11 in water containing $2 \mu \mathrm{M}$ of ABA. (D) Germination rate of transgenic rice and $\mathrm{ZH} 11$ rice seed in water containing $2 \mu \mathrm{M}$ of ABA. (E) The shoot growth of transgenic rice showed hypersensitivity to exogenous ABA. (F) Relative shoot length of transgenic rice and ZH11 with the addition of exogenous ABA. Three biological replicates were used for performed for each experiment. Representative graphs are shown ( $n=20$ seeds in each experiment). ${ }^{*}, p<0.05$ and **, $p<0.01$ (Student's $t$-test).

\subsection{Expression Analysis of Stress-Related Genes in ZmHsf05 Transgenic Rice}

In order to further study the molecular mechanism of drought tolerance provided by overexpressing the $\mathrm{ZmHsf05}$ in transgenic rice, several genes responsive to stress were selected for the analysis of their transcription levels. As shown in Figure 9, a key gene in ABA synthesis (OsNCED3, Os07g0154100) [16], an abscisic stress-ripening protein 5 gene which may be involved in the regulation of plant growth and drought tolerance (OsASR5, Os11g0167800) [13]; a late embryogenesis abundant (LEA) gene (OsLEA3, Os06g0324400) [50], and an anther-specific aspartic protease involving in tapetal programmed cell death (OsAP37, Os04g0448500) [51] were selected. Their expression levels were investigated in ZH11 and transgenic lines by RT-qPCR before and after the drought stress was initiated. We found that after drought treatment, the expression levels of Os- 
NCED3, OsASR5, OSLEA3, and OsAP37 were significantly elevated in transgenic rice compared with those in wild-type rice ZH11 (Figure 9).
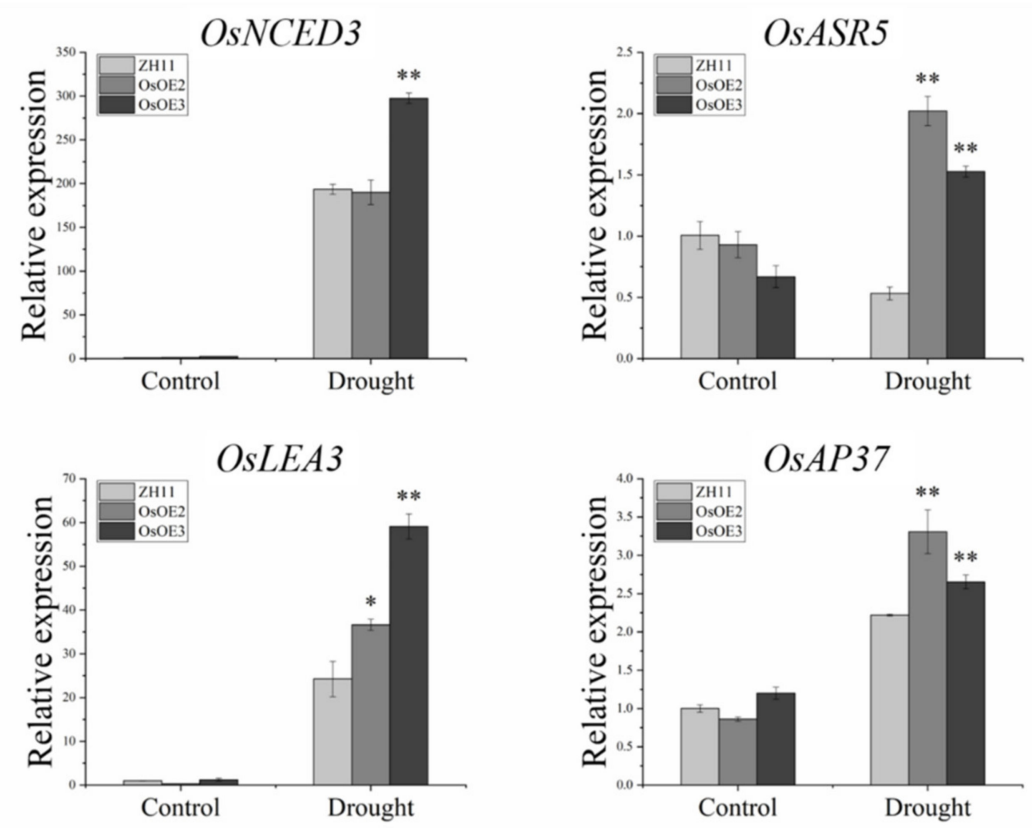

Figure 9. Expression analysis of ABA-related and drought-related genes in transgenic rice after drought treatment. Three biological replicates were used for each experiment. The OsActin-1 gene was used as the internal control for normalization. Vertical bars indicate means \pm SEs $(n=3)$. ${ }^{*}, p<0.05 ;{ }^{* *}, p<0.01$ (Student's $t$-test).

\section{Discussion}

Hsfs are common among different eukaryotic organisms and play central roles in the plant response network $[17,23,28]$. Compared with those in other eukaryotes, Hsf families in plant species, especially in angiosperm, exhibited an expanded and varied number of genes, indicating that $H s f s$ may be involved in a more sophisticated and highly regulated transcriptional system allowing plants to cope with adverse environmental stresses $[28,36]$. Hsfs are made up of constitute three subfamilies-namely, Class A, Class B, and Class C [27]. Class A Hsfs were reported in transcriptional activation to various stress responses, whereas, Class B Hsfs served as repressors of gene expression or transcriptional coactivators with Class A genes. It has been reported that $H s f s$ genes are maintained in inactive states, forming complexes with heat shock proteins [52]. Upon stress, Hsf genes can be released from the complex and activated, eventually binding to the promoters of Hsf-responsive genes via conserved binding motifs to transcriptionally regulate types of stress-responsive genes $[23,27,29-31]$. In the present study, ZmHsf05 was found to belong to the Class A2 family, showing a clear homology to OsHsfA2e (Figure 1B). ZmHsf05 was found to harbor conserved DBD, OD, NLS and AHA domains. Consistent with the existence of the NLS and AHA domains, ZmHsf05 has been proven to be located in the nucleus in maize protoplasts and to exhibit auto activation activity in yeast. Moreover, ZmHsf05 was upregulated when the seedlings were exposed to diverse types of stresses. All these results indicated that $\mathrm{ZmHsf05}$ could be a promising transcriptional activator for enhancing adaptability to diverse types of stress tolerance.

In recent years, some maize heat shock transcription factors have been reported to respond to various abiotic stresses such as $\mathrm{ZmHsf01} \mathrm{[38]} \mathrm{and} \mathrm{ZmHsfo4} \mathrm{[37].} \mathrm{OsHsfA2e,}$

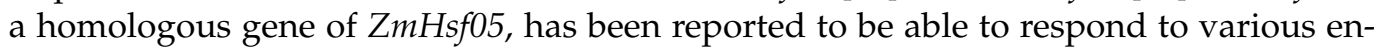
vironmental stresses [53]. In the present study, ZmHsf05 was induced by various environmental stresses, including high temperature, drought (desiccation), high salt levels and ABA (Figure 2), suggesting the versatile functions of ZmHsf05, similar to with its 
orthologous genes OsHsfA2e. To decipher its functional characterization, $\mathrm{ZmHsf05}$ was overexpressed in rice. In the present study, transgenic rice lines overexpressing $\mathrm{ZmHsf05}$ clearly exhibited a better phenotypic performance under conditions of severe drought stress (Figures 6 and 7A). Furthermore, ZmHsf05 transgenic lines accumulated more proline, and showed lower leaf water loss rate compared to wild type plants in drought condition. With less water loss, plants could be relatively resistant to drought stress. Additionally, proline is an important kind of compatible osmolytes and could compromise cellular impairment upon osmotic or drought stress [46]. Thus, we can conclude that $\mathrm{ZmHsf05}$ improves the ability to reduce water loss from leaves and stimulates the proline accumulation to maintain cellular osmotic balance upon drought or osmotic stress. Thus, $\mathrm{ZmHsf05}$ was found to be a positive regulator in response to drought stress and enhance drought tolerance (Figures 6 and 7A).

$\mathrm{ABA}$ acts as a central regulator in drought stress, seed germination, and relative water loss. Thus, we further investigated whether $\mathrm{ZmHsf05}$ functions through ABAdependent pathways or not. As expected, rice overexpressing $\mathrm{ZmHsf05}$ was found to be more sensitive to ABA than ZH11, with delayed seed germination courses and a shorter shoot height under ABA treatment (Figure 8). OsNCED3 (Os07g0154100), encoding 9cis-epoxycarotenoid dioxygenase, which was considered to be the key enzyme in the ABA synthesis pathway [16,54], was significantly upregulated in $\mathrm{ZmHsf05}$ transgenic rice (Figure 9). Moreover, the mRNA expression level of OsLEA3 (Os06g0324400) [51], a key factor in ABA-induced antioxidant defense, was significantly higher than that in $\mathrm{ZmHsf05}$ transgenic rice compared to ZH11. We also found that OsASR5, which plays multiple roles in response to drought stress by regulating the ABA biosynthesis pathway, was greatly changed upon drought stress. Collectively, we can state that $\mathrm{ZmHsf05}$ promotes plant sensitivity to ABA and positively regulates the transcription level of ABA- and stressresponsive genes, strongly indicating $\mathrm{ZmHsf05}$ positively regulates drought stress response in an ABA-dependent manner.

As most important crops in the world, the stabilization of rice and maize yield would be of great benefit for food security. $\mathrm{ZmHsf05}$ could be a promising drought-resistant gene for rice and maize breeding. Ectopic overexpression of $\mathrm{ZmHsf05}$ gene in rice may help us to acquire a modest comprehensive knowledge about the molecular function of $\mathrm{ZmHsf05}$ gene in maize. It is hoped that our study could provide a theoretical basis for the further functional characterization of $H s f$ genes in maize.

\section{Conclusions}

In general, the present study aims to investigate the molecular characterization and

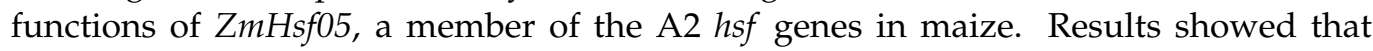
$\mathrm{ZmHsf05}$ located in the nucleus and has transactivation ability in yeast. Moreover, the mRNA level of $\mathrm{ZmHsf05}$ was affected by diverse abiotic stress. Overexpressing $\mathrm{ZmHsf05}$ in rice could significantly promote the drought tolerance of transgenic rice and significantly increased sensitivity to ABA treatment. Additionally, the transcription levels of ABA- and drought- responsive genes were significantly increased after drought stress in transgenic rice. Overall, $\mathrm{ZmHsf05}$ was suggested to positively regulate plant drought tolerance in an ABA-dependent manner. The present study would provide demonstrates a promising gene resource for rice and maize breeding. Lastly, it is hoped that this study can provide a theoretical basis for the further functional characterization of Hsf genes in maize and contribute to the improvement of global crop yield security. 
Supplementary Materials: The following are available online at https:/ / www.mdpi.com/article / 10.3390 / genes12101568/s1, Figure S1. Identification of positive transgenic rice seedlings overexpressing ZmHsf05 gene. (A) GUS staining of transgenic rice leaves. (B) PCR amplification of GUS gene for transgenic rice lines. (C) Quantitative detection of $\mathrm{ZmHsf05}$ gene expression in transgenic rice. (D) Semi-quantitative detection of $\mathrm{ZmHsf05}$ gene expression in transgenic rice lines. The OsActin-1 gene was used as the internal control for normalization. M stands for maker. Vertical bars indicate means \pm S.E. $(n=3)$. Table S1. The sequence of primers used in this study.

Author Contributions: Conceptualization, H.J. and W.S.; methodology, W.S.; funding Acquisition, W.S. and H.J.; investigation, W.S., Q.L., L.C., F.S. and Y.C.; data curation, W.S., Q.L., L.C., F.S. and Y.C.; visualization, Q.L., L.C. and F.S.; writing-Original Draft Preparation, W.S. and Q.L.; writingReview \& Editing Supervision, H.J. and W.S.; resources, H.J.; project administration, H.J. All authors had read and approved the final manuscript.

Funding: This research was funded by National Natural Science Foundation of China (grant number 32001499, 31771805) and Natural Science Foundation of Anhui Province (grant number 1908085QC106).

Data Availability Statement: We obtained the full-length CDS sequence of the $\mathrm{ZmHsf05}$ gene from the online database Phytozome (https:/ / phytozome.jgi.doe.gov/pz/portal.html accessed on 18 April 2014). We use the online website ExPASy (https:/ / web.expasy.org/compute_pi/ accessed on 1 July 2020) to predict translation of the protein of the $\mathrm{ZmHsf05}$ gene. All other data supporting the results are included within the article and its Additional files.

Acknowledgments: Thanks to the National Engineering Laboratory of Crop Stress Resistance Breeding of Anhui Agricultural University for providing instruments and equipment. Thanks to all the people and units involved in this work.

Conflicts of Interest: The authors declare no conflict of interest.

\section{References}

1. Smertenko, A. Can Peroxisomes Inform Cellular Response to Drought? Trends Plant Sci. 2017, 22, 1005-1007. [CrossRef]

2. Lobell, D.B.; Roberts, M.J.; Schlenker, W.; Braun, N.; Little, B.B.; Rejesus, R.M.; Hammer, G.L. Greater sensitivity to drought accompanies maize yield increase in the U.S. Midwest. Science 2014, 344, 516-569. [CrossRef]

3. Salekdeh, G.H.; Reynolds, M.; Bennett, J.; Boyer, J. Conceptual framework for drought phenotyping during molecular breeding. Trends Plant Sci. 2009, 14, 488-496. [CrossRef]

4. Rueda, M.; Godoy, O.; Hawkins, B.A. Spatial and evolutionary parallelism between shade and drought tolerance explains the distributions of conifers in the conterminous United States. Glob. Ecol. Biogeogr. 2017, 26, 31-42. [CrossRef]

5. Ripullone, F.; Borghetti, M.; Raddi, S.; Vicinelli, E.; Baraldi, R.; Guerrieri, M.R.; Nole, A.; Magnani, F. Physiological and structural changes in response to altered precipitation regimes in a Mediterranean macchia ecosystem. Trees 2009, 23, 823-834. [CrossRef]

6. Dong, X.J.; Zhang, X.S. Some observations of the adaptations of sandy shrubs to the arid environment in the Mu Us Sandland: Leaf water relations and anatomic features. J. Arid Environ. 2001, 48, 41-48. [CrossRef]

7. Fraser, L.H.; Greenall, A.; Carlyle, C.; Turkington, R.; Friedman, C.R. Adaptive phenotypic plasticity of Pseudoroegneria spicata: Response of stomatal density, leaf area and biomass to changes in water supply and increased temperature. Ann. Bot. 2009, 103, 769-775. [CrossRef]

8. Xu, Z.; Zhou, G. Responses of leaf stomatal density to water status and its relationship with photosynthesis in a grass. J. Exp. Bot. 2008, 59, 3317-3325. [CrossRef]

9. Lopes, M.S.; Reynolds, M.P. Partitioning of assimilates to deeper roots is associated with cooler canopies and increased yield under drought in wheat. Funct. Plant Biol. 2010, 37, 147-156. [CrossRef]

10. De Smet, I.; Signora, L.; Beeckman, T.; Inze, D.; Foyer, C.H.; Zhang, H. An abscisic acid-sensitive checkpoint in lateral root development of Arabidopsis. Plant J. Cell Mol. Biol. 2003, 33, 543-555. [CrossRef]

11. Mukarram, M.; Choudhary, S.; Kurjak, D.; Petek, A.; Khan, M.M.A. Drought: Sensing, signalling, effects and tolerance in higher plants. Physiol. Plant 2021, 172, 1291-1300. [CrossRef] [PubMed]

12. Tuteja, N. Abscisic Acid and abiotic stress signaling. Plant Signal Behav. 2007, 2, 135-138. [CrossRef] [PubMed]

13. Li, J.; Li, Y.; Yin, Z.; Jiang, J.; Zhang, M.; Guo, X.; Ye, Z.; Zhao, Y.; Xiong, H.; Zhang, Z.; et al. OsASR5 enhances drought tolerance through a stomatal closure pathway associated with ABA and $\mathrm{H}(2) \mathrm{O}(2)$ signalling in rice. Plant Biotechnol. J. 2017, 15, 183-196. [CrossRef]

14. Yan, H.; Jia, H.; Chen, X.; Hao, L.; An, H.; Guo, X. The cotton WRKY transcription factor GhWRKY17 functions in drought and salt stress in transgenic Nicotiana benthamiana through ABA signaling and the modulation of reactive oxygen species production. Plant Cell Physiol. 2014, 55, 2060-2076. [CrossRef] [PubMed] 
15. Sato, H.; Takasaki, H.; Takahashi, F.; Suzuki, T.; Iuchi, S.; Mitsuda, N.; Ohme-Takagi, M.; Ikeda, M.; Seo, M.; Yamaguchi-Shinozaki, K.; et al. Arabidopsis thaliana NGATHA1 transcription factor induces ABA biosynthesis by activating NCED3 gene during dehydration stress. Proc. Natl. Acad. Sci. USA 2018, 115, E11178-E11187. [CrossRef] [PubMed]

16. Hwang, S.-G.; Chen, H.-C.; Huang, W.-Y.; Chu, Y.-C.; Shii, C.-T.; Cheng, W.-H. Ectopic expression of rice OsNCED3 in Arabidopsis increases ABA level and alters leaf morphology. Plant Sci. 2010, 178, 12-22. [CrossRef]

17. Manna, M.; Thakur, T.; Chirom, O.; Mandlik, R.; Deshmukh, R.; Salvi, P. Transcription factors as key molecular target to strengthen the drought stress tolerance in plants. Physiol. Plantarum 2021, 172, 847-868. [CrossRef]

18. Long, L.; Gao, W.; Xu, L.; Liu, M.; Luo, X.; He, X.; Yang, X.; Zhang, X.; Zhu, L. GbMPK3, a mitogen-activated protein kinase from cotton, enhances drought and oxidative stress tolerance in tobacco. Plant Cell Tissue Organ Cult. 2014, 116, 153-162. [CrossRef]

19. Zhang, X.; Wang, L.; Meng, H.; Wen, H.; Fan, Y.; Zhao, J. Maize ABP9 enhances tolerance to multiple stresses in transgenic Arabidopsis by modulating ABA signaling and cellular levels of reactive oxygen species. Plant Mol. Biol. 2011, 75, 365-378. [CrossRef]

20. Zhang, L.; Xiao, S.; Li, W.; Feng, W.; Li, J.; Wu, Z.; Gao, X.; Liu, F.; Shao, M. Overexpression of a Harpin-encoding gene hrf1 in rice enhances drought tolerance. J. Exp. Bot. 2011, 62, 4229-4238. [CrossRef]

21. Huang, J.; Sun, S.J.; Xu, D.Q.; Yang, X.; Bao, Y.M.; Wang, Z.F.; Tang, H.J.; Zhang, H. Increased tolerance of rice to cold, drought and oxidative stresses mediated by the overexpression of a gene that encodes the zinc finger protein ZFP245. Biochem. Biophys. Res. Commun. 2009, 389, 556-561. [CrossRef] [PubMed]

22. Tyerman, S.D.; Niemietz, C.M.; Bramley, H. Plant aquaporins: Multifunctional water and solute channels with expanding roles. Plant Cell Environ. 2002, 25, 173-194. [CrossRef] [PubMed]

23. Scharf, K.D.; Berberich, T.; Ebersberger, I.; Nover, L. The plant heat stress transcription factor (Hsf) family: Structure, function and evolution. Biochim. Biophys. Acta 2012, 1819, 104-119. [CrossRef] [PubMed]

24. Nover, L.; Bharti, K.; Doring, P.; Mishra, S.K.; Ganguli, A.; Scharf, K.D. Arabidopsis and the heat stress transcription factor world: How many heat stress transcription factors do we need? Cell Stress Chaperon 2001, 6, 177-189. [CrossRef]

25. Zhang, J.; Li, Y.; Jia, H.X.; Li, J.B.; Huang, J.; Lu, M.Z.; Hu, J.J. The heat shock factor gene family in Salix suchowensis: A genomewide survey and expression profiling during development and abiotic stresses. Front. Plant Sci. 2015, 6, 748. [CrossRef]

26. Huang, Y.C.; Niu, C.Y.; Yang, C.R.; Jinn, T.L. The Heat Stress Factor HSFA6b Connects ABA Signaling and ABA-Mediated Heat Responses. Plant Physiol. 2016, 172, 1182-1199. [CrossRef]

27. Kotak, S.; Port, M.; Ganguli, A.; Bicker, F.; von Koskull-Doring, P. Characterization of C-terminal domains of Arabidopsis heat stress transcription factors (Hsfs) and identification of a new signature combination of plant class A Hsfs with AHA and NES motifs essential for activator function and intracellular localization. Plant J. Cell Mol. Biol. 2004, 39, 98-112. [CrossRef]

28. Guo, M.; Liu, J.H.; Ma, X.; Luo, D.X.; Gong, Z.H.; Lu, M.H. The Plant Heat Stress Transcription Factors (HSFs): Structure, Regulation, and Function in Response to Abiotic Stresses. Front. Plant Sci. 2016, 7, 114. [CrossRef]

29. Doring, P.; Treuter, E.; Kistner, C.; Lyck, R.; Chen, A.; Nover, L. The role of AHA motifs in the activator function of tomato heat stress transcription factors HsfA1 and HsfA2. Plant Cell 2000, 12, 265-278. [CrossRef]

30. Liu, H.C.; Liao, H.T.; Charng, Y.Y. The role of class A1 heat shock factors (HSFA1s) in response to heat and other stresses in Arabidopsis. Plant Cell Environ. 2011, 34, 738-751. [CrossRef]

31. Hwang, S.M.; Kim, D.W.; Woo, M.S.; Jeong, H.S.; Son, Y.S.; Akhter, S.; Choi, G.J.; Bahk, J.D. Functional characterization of Arabidopsis HsfA6a as a heat-shock transcription factor under high salinity and dehydration conditions. Plant Cell Environ. 2014, 37, 1202-1222. [CrossRef] [PubMed]

32. Personat, J.M.; Tejedor-Cano, J.; Prieto-Dapena, P.; Almoguera, C.; Jordano, J. Co-overexpression of two Heat Shock Factors results in enhanced seed longevity and in synergistic effects on seedling tolerance to severe dehydration and oxidative stress. BMC Plant Biol. 2014, 14, 56. [CrossRef]

33. Bi, H.; Zhao, Y.; Li, H.; Liu, W. Wheat Heat Shock Factor TaHsfA6f Increases ABA Levels and Enhances Tolerance to Multiple Abiotic Stresses in Transgenic Plants. Int. J. Mol. Sci. 2020, 21, 3121. [CrossRef] [PubMed]

34. Zhu, M.D.; Zhang, M.; Gao, D.J.; Zhou, K.; Tang, S.J.; Zhou, B.; Lv, Y.M. Rice OsHSFA3 Gene Improves Drought Tolerance by Modulating Polyamine Biosynthesis Depending on Abscisic Acid and ROS Levels. Int. J. Mol. Sci. 2020, 21, 1857. [CrossRef] [PubMed]

35. Wang, N.; Liu, W.; Yu, L.; Guo, Z.; Chen, Z.; Jiang, S.; Xu, H.; Fang, H.; Wang, Y.; Zhang, Z.; et al. Heat Shock Factor A8a Modulates Flavonoid Synthesis and Drought Tolerance. Plant Physiol. 2020, 184, 1273-1290. [CrossRef] [PubMed]

36. Zhang, H.; Li, G.; Fu, C.; Duan, S.; Hu, D.; Guo, X. Genome-wide identification, transcriptome analysis and alternative splicing events of Hsf family genes in maize. Sci. Rep. 2020, 10, 8073. [CrossRef]

37. Jiang, Y.; Zheng, Q.; Chen, L.; Liang, Y.; Wu, J. Ectopic overexpression of maize heat shock transcription factor gene ZmHsf04 confers increased thermo and salt-stress tolerance in transgenic Arabidopsis. Acta Physiol. Plant. 2018, 40, 1-12.

38. Zhang, H.; Li, G.; Hu, D.; Zhang, Y.; Zhang, Y.; Shao, H.; Zhao, L.; Yang, R.; Guo, X. Functional characterization of maize heat shock transcription factor gene ZmHsf01 in thermotolerance. PeerJ 2020, 8, e8926.

39. Bateman, A.; Birney, E.; Durbin, R.; Eddy, S.R.; Finn, R.D.; Sonnhammer, E.L. Pfam 3.1: 1313 multiple alignments and profile HMMs match the majority of proteins. Nucleic Acids Res. 1999, 27, 260-262.

40. Kumar, S.; Stecher, G.; Tamura, K. MEGA7: Molecular Evolutionary Genetics Analysis Version 7.0 for Bigger Datasets. Mol. Biol. Evol. 2016, 33, 1870-1874. 
41. Robert, X.; Gouet, P. Deciphering key features in protein structures with the new ENDscript server. Nucleic Acids Res. 2014, 42, W320-W324. [CrossRef]

42. Jumper, J.; Evans, R.; Pritzel, A.; Green, T.; Figurnov, M.; Ronneberger, O.; Tunyasuvunakool, K.; Bates, R.; Zidek, A.; Potapenko, A.; et al. Highly accurate protein structure prediction with AlphaFold. Nature 2021, 596, 583-589. [CrossRef]

43. Tang, Y.; Liu, K.; Zhang, J.; Li, X.; Xu, K.; Zhang, Y.; Qi, J.; Yu, D.; Wang, J.; Li, C. JcDREB2, a Physic Nut AP2/ERF Gene, Alters Plant Growth and Salinity Stress Responses in Transgenic Rice. Front. Plant Sci. 2017, 8, 306. [CrossRef] [PubMed]

44. Ye, S.W.; Cai, C.Y.; Ren, H.B.; Wang, W.J.; Xiang, M.Q.; Tang, X.S.; Zhu, C.P.; Yin, T.F.; Zhang, L.; Zhu, Q. An Efficient Plant Regeneration and Transformation System of Ma Bamboo (Dendrocalamus latiflorus Munro) Started from Young Shoot as Explant. Front. Plant Sci. 2017, 8, 1298. [CrossRef] [PubMed]

45. Vandesompele, J.; De Preter, K.; Pattyn, F.; Poppe, B.; Van Roy, N.; De Paepe, A.; Speleman, F. Accurate normalization of real-time quantitative RT-PCR data by geometric averaging of multiple internal control genes. Genome Biol. 2002, 3, 1-12. [CrossRef] [PubMed]

46. Wei, S.; Hu, W.; Deng, X.; Zhang, Y.; Liu, X.; Zhao, X.; Luo, Q.; Jin, Z.; Li, Y.; Zhou, S.; et al. A rice calcium-dependent protein kinase OsCPK9 positively regulates drought stress tolerance and spikelet fertility. BMC Plant Biol. 2014, 14, 133. [CrossRef]

47. Cao, J.M.; Yao, D.M.; Lin, F.; Jiang, M.Y. PEG-mediated transient gene expression and silencing system in maize mesophyll protoplasts: A valuable tool for signal transduction study in maize. Acta Physiol. Plant. 2014, 36, 1271-1281. [CrossRef]

48. Tang, Q.Y.; Zhang, C.X. Data Processing System (DPS) software with experimental design, statistical analysis and data mining developed for use in entomological research. Insect Sci. 2013, 20, 254-260. [CrossRef]

49. Lin, Y.X.; Jiang, H.Y.; Chu, Z.X.; Tang, X.L.; Zhu, S.W.; Cheng, B.J. Genome-wide identification, classification and analysis of heat shock transcription factor family in maize. BMC Genom. 2011, 12, 76. [CrossRef]

50. Hu, T.Z. OsLEA3, a late embryogenesis abundant protein gene from rice, confers tolerance to water deficit and salt stress to transgenic rice. Russ. J. Plant Physiol. 2008, 55, 530-537. [CrossRef]

51. Mao, C.; Ding, J.; Zhang, B.; Xi, D.; Ming, F. OsNAC2 positively affects salt-induced cell death and binds to the OsAP37 and OsCOX11 promoters. Plant J. Cell Mol. Biol. 2018, 94, 454-468. [CrossRef] [PubMed]

52. Hahn, A.; Bublak, D.; Schleiff, E.; Scharf, K.D. Crosstalk between Hsp90 and Hsp70 chaperones and heat stress transcription factors in tomato. Plant Cell 2011, 23, 741-755. [CrossRef] [PubMed]

53. Yokotani, N.; Ichikawa, T.; Kondou, Y.; Matsui, M.; Hirochika, H.; Iwabuchi, M.; Oda, K. Expression of rice heat stress transcription factor OsHsfA2e enhances tolerance to environmental stresses in transgenic Arabidopsis. Planta 2008, 227, 957-967. [CrossRef]

54. Jiang, D.; Zhou, L.; Chen, W.; Ye, N.; Xia, J.; Zhuang, C. Overexpression of a microRNA-targeted NAC transcription factor improves drought and salt tolerance in Rice via ABA-mediated pathways. Rice 2019, 12, 76. [CrossRef] [PubMed] 